\title{
MALLOTUS KONGKANDAE (EUPHORBIACEAE): NEW RECORD FOR CHINA
}

\author{
S.E.C. SIERRA \& P.C. VAN WELZEN \\ Nationaal Herbarium Nederland, Universiteit Leiden branch, \\ P.O. Box 9514, 2300 RA Leiden, The Netherlands; \\ e-mail: sierra@nhn.leidenuniv.nl,welzen@nhn.leidenuniv.nl
}

\section{SUMMARY}

Mallotus kongkandae Welzen \& Phattar. was thought to be endemic to Thailand, but it also occurs in China, though known under other names. The new list of synonyms, a distribution map, notes on habitat and ecology, and collector details are included.

The species M. kongkandae Welzen \& Phattar. was described as an endemic species of Thailand (Van Welzen \& Phattarahirankanok, 2001). Hwang (1985) published the variety M. philippensis (Lam.) Müll. Arg. var. mengliangensis C.Y. Wu ex S.M. Hwang. Later, Kiu (1993) reduced it to M. pallidus. Hwang (1996) disagreed and included M. pallidus under the list of doubtful taxa for the Flora of China. Sierra et al. (2005: 230, 240) agreed with Hwang (1996) that var. mengliangensis does not represent M. pallidus and, because the type was not seen, the interpretation of the name remained uncertain. Fortunately, the type and additional collections became available and it appears that $M$. philippensis var. mengliangensis is conspecific with M. kongkandae. The epithet menglianensis may be older than kongkandae, but priority rules have to be applied per taxonomic level. This taxon appears to be a good species, therefore, the name kongkandae has to be applied.

Diagnostic characters for recognition of this species are leaves with a tomentose indument on the lower surface, composed of (whitish) stellate and orange glandular hairs (the latter sometimes green when dried), two basal extrafloral nectaries on the upper surface, fruits densely covered with glandular hairs, and a thick fruit wall of 2-3 $\mathrm{mm}$. For a complete description see Sierra et al. (2005), Van Welzen \& Phattarahirankanok (2001) (see also http://www.nationaalherbarium.nl/thaieuph/ThMspecies/ThMallotusT.htm).

Mallotus kongkandae Welzen \& Phattar. - Map 1

Mallotus kongkandae Welzen \& Phattar. (2001) 67; S.E.C. Sierra, Welzen \& Slik (2005) 224. - Type: Chayamarit et al. 1551 (holo L; iso AAU, BKF, K), Thailand, Northern, Kamphaeng Phet Prov., Mae Wong National Park, Chong Yen.

Mallotus philippensis (Lam.) Müll. Arg. var. mengliangensis C.Y. Wu ex S.M. Hwang (1985) 294;

(1996) 45. - Type: Y.H. Li 3543 (holo IBSC), China, Yunnan, Xishuangbanna.

Mallotus pallidus auct. non (Airy Shaw) Airy Shaw: Kiu (1993) 74. 


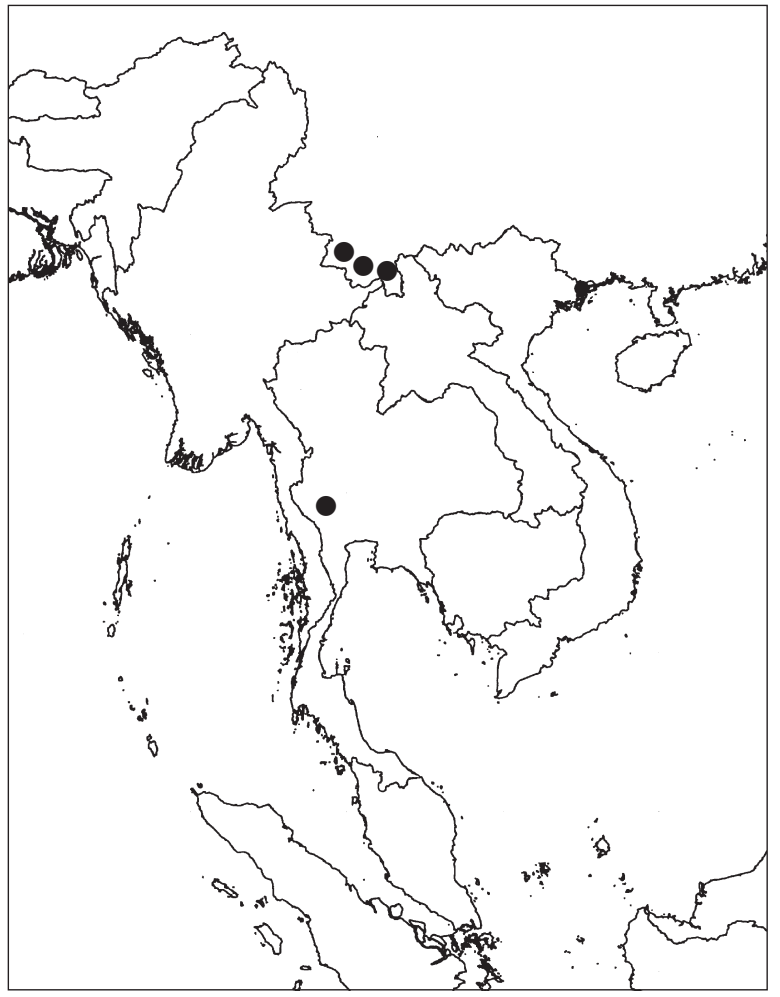

Map 1. Distribution of Mallotus kongkandae Welzen \& Phattar.

Distribution - Thailand (Northern) and China (Yunnan).

Habitat \& Ecology - Altitude c. 1300-1400 m. Fruiting from June to December. Identification list:

Chayamarit et al. 1551; Y.H. Li 3543; Menglian exp. 10097; P.I. Mao 7272.

\section{ACKNOWLEDGEMENTS}

The directors of ISCB and L are thanked for lending their material. Special thanks are due to Ding Hou for help with the Chinese translations.

\section{REFERENCES}

Hwang, S.M. 1985. New material of Mallotus L. from China. Acta Phytotax. Sin. 23: 293-301. Hwang, S.M. 1996. Mallotus. In: H.S. Kiu, Flora Reipublicae Popularis Sinicae 44, 2: 13-45. Science Press, Peking.

Kiu, H. S. 1993. Additions and corrections to the Euphorbiaceae of Yunnan province. J. S. W. Forest. Coll. 13: 73-78.

Sierra, S.E.C., P.C. van Welzen \& J.W.F. Slik. 2005. A taxonomic revision of Mallotus section Philippinenses (former section Rottlera - Euphorbiaceae) in Malesia and Thailand. Blumea 50: 221-248.

Van Welzen, P.C \& K. Phattarahirankanok. 2001. Mallotus kongkandae (Euphorbiaceae), a new species from Thailand. Blumea 46: 67-69. 